\title{
Coir Dust- Based Bio-organic Fertilizer: Its Effect on the Growth and Yield of Cucumber
}

\author{
Eleanor L. Cacacho* and Ronel C. Dela Cruz \\ Faculty, College of Agriculture, Cagayan State University, Sanchez Mira, 3518 Cagayan Valley, Philippines; \\ Eleanorcacachocsu@gmail.com, ronelcdelacruz01@gmail.com
}

\begin{abstract}
Objectives: To produce the coir dust-based bio-organic fertilizer through bioconversion using Effective Microorganism (EM) and to investigate its effect on the growth and yield of cucumber and its cost of production and return of investment. Methods/Statistical Analysis: The Randomized Complete Block Design (RCBD) was used in the study. EM Activation, Formulation of Inoculant and Bio Conversion were also applied. All materials were prepared by the researchers to produce coir dust-based bio-organic fertilizer. It also utilized Land Preparation, Application of Coir Dust-based bio-organic Fertilizer, Planting and Care of Plants. Data were subjected to Analysis of Variance (ANOVA) and Least Significant Differences (LSD) using the Randomized Complete Block Design (RCBD). Findings: Application of 25 ton/ha increased the number of fruits of cucumber. Applying coir dust-based bio-organic fertilizer to cucumber reduced the number of damaged fruits. As regards yield of cucumber, a significant increase of yield had been found to cucumber applied with coir dust-based bio-organic fertilizer at the rate of 25 ton/ha. Insignificant results were found on the number of leaves at maturity, length and diameter of fruits and number of damaged fruits. Cucumber applied with 15 ton/ha obtained the highest income with a return of investment (ROI) of 31.5\%. Application of coir dust-based-organic fertilizer increased the number of fruits, undamaged fruits and yield of cucumber. Application/Improvements: The production of coir dust-based bio-organic fertilizers a worthy source of information to farmers to maximize the use of coco dusts. Likewise, the utilization/application of such bio-organic fertilizer can increase the number of fruits, undamaged fruits, and yield of cucumber, which is very favorable to cucumber growers.
\end{abstract}

Keywords: Bio-organic, Coir Dust, Cucumber, Effective Organism, Organic Fertilizer

\section{Introduction}

Sanchez Mira is one of the towns of Northwestern Cagayan where coconut trees abundantly thrive and flourish. It is known for its wide coconut areas, this town is considered as major producer of coconut products in Region 02 . Around 6,700 ha of the town land is utilized for coconut production and composed of 9,734 farmers depending on their income from coconut.

The coco meat is used to obtain coco flour, desiccated coconut, coconut milk, coconut chips, candies, local sweetened shredded coconut meat, copra and animal feeds.

Aside from food products there are also non-food products from the coconut husk like coco coir. This coco coir is the fibrous material in the coconut husk between the outer coverings of the shell. Through processing and aid of necessary equipment, one can harvest coco fiber and coco peat from coconut husk. The coco peat also known as coir dust is the spongy lightweight particle which falls out when the fiber is separated during the extraction of coconut fiber ${ }^{1}$. The coir dusts make it suitable and stable supply for cottage industries that produce brushes, doormats, carpets, bags, ropes ${ }^{2}$.

Despite its many uses, farmers could not practice to manufacture these products because of lack of necessary equipment, thus still bulky of coir dusts are becoming wastes of the town because people value more its fiber which can be made into various products and its coir

*Author for correspondence 
dust usually left unutilized and become waste. According to an authority there is about $30 \%$ or 300 grams of fiber extracted from coconut husk and the rest is coir dust ${ }^{3}$, thus the volume of coir dust which becomes waste if unutilized is greater than fiber. Aside from improper management, coir dust can cause polyphenol leaching that can pollute the land and ground water ${ }^{4}$. The challenge is to find another way on how to utilize coir dust waste that can increase the income of coconut farmers.

The production of bio fertilizer through bio conversion is being considered as a potential option in the hierarchy of integrated solid waste management that involves the stabilization of organic material by the action of earthworms ${ }^{5}$. Bio conversion using earthworm can produce value added to material and reduce quantity of waste. Biofertilizers are excellent alternative to chemical fertilizers which provide nutrients through the action of nitrogen fixation, solubilizing phosphorus and trigger plant growth though the synthesis of growth promoting essence ${ }^{6}$. Coir dust is lignocellulosic waste materials which consist of higher amount of lignin, cellulose and hemicelluloses that limitits degradation $^{7}$. Due to Effective Microorganism (EM) as a microbial inoculant promotes decomposition of waste materials for it contains lactic acid bacteria that produce lactic acid that enhances decomposition of organic matter $\stackrel{8}{\text {. }}$.

The value of a bio fertilizer is largely dependent on the waste material to be decomposed. Coir dust has a good water and air holding capacity, that is, it holds eight to nine times its weight in water and even when saturated it typically still holds around $22 \%$ air with excellent cation exchange ${ }^{2}$.

Hence, the study aimed to maximize and improve the use of coir dust through bioconversion into bio-organic fertilizer using Effective Microorganism (EM).

\section{Importance of the Study}

The study determined the potential of coir dust as bioorganic fertilizer to cucumber through bio conversion using Effective Microorganism (EM).

The study was delimited on the growth and yield of cucumber under Cagayan State University at Sanchez Mira conditions particularly: Number of leaves at maturity, number of fruits, length of fruits, diameter of fruits, number of damaged fruits, number of undamaged fruits, yield in $\mathrm{kg} / \mathrm{ha}$, cost and return analysis.

The findings of this study are significant to coconut farmers for it could be a good source of information that would make them maximize the use of coco dust and have a source of additional income; vegetable growers are likewise benefited for it could be the source of information in producing bio-organic fertilizer that may increase the fertility of their soil and enhances the quality of their produce; also, the results of such study are remarkable to researchers for it could be a good source of knowledge and ideas for further verification and related studies.

\section{Objectives of the Study}

Generally, the study produced bio-organic fertilizer through bio conversion using Effective Microorganism (EM). Specifically, the study determined the effect of coir dust as bio-organic fertilizer to cucumber in terms of:

- Growth.

- Number of leaves at maturity (pcs).

- Yield.

- Number of fruits (pcs).

- Length of fruits $(\mathrm{cm})$.

- Diameter of fruits ( $\mathrm{mm}$ ).

- Number of damaged fruit (pcs).

- Number of undamaged fruit (pcs).

- Yield in hectare (kg).

- Cost and return analysis (PhP).

\section{Methodology}

\subsection{Research Design}

The Randomized Complete Block Design (RCBD) was used in the study. The area of 494 square meters was divided in three (3) blocks representing the replications and further subdivided each block into four (4) plots representing the treatments: $\mathrm{T}_{0}$ - Control (unfertilized);

$\mathrm{T}_{1}-15$ tons/ha; $\mathrm{T}_{2}-20$ tons/ha; $\mathrm{T}_{3}-25$ tons/ha.

\subsection{EM Activation, Formulation of Inoculant and Bio Conversion}

All materials were prepared by the researchers to produce coir dust based bio-organic fertilizer. The process of fermenting EM was based from Tetraganix ${ }^{10}$. One part EM, 1 part molasses, 20 parts water were mixed in a clean air tight container, fermented for 3-5 days at room temperature. The product is the Effective Microorganism Activated Solution (EMAS).

To formulate the Effective Microorganism Based Inoculant (EMBI), $8 \mathrm{~kg}$ rice bran, $8 \mathrm{~kg}$ Carbonized Rice 
Hull (CRH) and 2.4 L EMAS were needed. The rice bran and $\mathrm{CRH}$ were mixed thoroughly before mixing to EMAS. The mixture was placed in a plastic container and was pressed to remove the air before it was covered to ferment for seven days.

Coir dust based bio-organic fertilizer was produced using the EMBI formulated by the researchers, $60 \%$ coir dust, $20 \%$ chicken dung, $10 \%$ bagingilog and $10 \%$ banana peelings. An ideal composting site-shaded, well drained and near source of water was selected. In piling the materials, the following steps were followed: 1 . Spread one third of the coir dust with $60 \%$ moisture content. Apply the required amount of inoculant on top $(0.5 \%$ of weight of the material in a layer); 2 . Spread evenly the chicken manure on top, water and inoculate; 3 . Repeat steps 1 and 2 but use bagingilog and banana peels instead of chicken manure. Apply the inoculant on top of the fourth layer combining the weight of materials in the fourth and fifth layers; 4 . As the topmost layer, spread evenly coir dust but do not inoculate. This serves as a buffer for odor; 5. Cover the heap with laminated plastic sack to prevent rainwater from getting into the pile. Incubate for 4-7 days; 6 . After 4-7 days, turn and mix thoroughly the materials. Water if needed during turning. Return the cover. Repeat step 6 at weekly interval; 7 . After three or four weeks, harvest the material. Ripe compost has dark brown to black color, no offensive smell, temperature is ambient and with $35 \%$ moisture content or lower. Screen the organic fertilizer through manual sieve or mechanical sifter; 8. Put BOF in $50 \mathrm{~kg}$ plastic-lined sack and seal. Do not pile directly on concrete flooring but provide wooden platform.

\subsection{Land Preparation, Application of Coir Dust-based Bio-organic Fertilizer, Planting and Care of Plants}

The area was weeded and plowed twice and harrowed ones at one week interval using a hand tractor. Seeds were sown in a seedling tray and placed in the nursery. Sown seeds were watered regularly in the morning. The plots were prepared based on the experimental design of the study. Each plot measured three (3) meters wide and four (4) meters long with fifty (50) $\mathrm{cm}$ distance each plot and one (1) meter each block.

Bio-organic fertilizer was applied basally in each plotone (1) week before transplanting of cucumber seedlings through broadcasting following the treatments of the study, specifically $\mathrm{T}_{0}-$ control, $\mathrm{T}_{1}-54 \mathrm{~kg}, \mathrm{~T}_{2}-72 \mathrm{~kg}$,
$\mathrm{T}_{3}-90 \mathrm{~kg}$ levels. Immediately after broadcasting, incorporation of the coir dust-based bio-organic fertilizer was done.

Hills were dug five (5) inches deep and four (4) inches in diameter, following the required planting distance of cucumber which is fifty (50) $\mathrm{cm}$ between hills and one hundred (100) $\mathrm{cm}$ between rows.

Two (2) weeks after sowing, seedlings were transplanted. This was done late in the afternoon and was watered immediately after transplanting.

The A-type trellis was placed starting three (3) days after transplanting. Bamboo sticks were used as posts and plastic straws to tie the posts.

The plants were watered regularly early or late in the afternoon of approximately equal volume of water to prevent wilting especially during extreme sunny days. This was regularly done until the crop reached its senescence stage.

One (1) week after transplanting, hilling up was done to break the clods around the plants and aerate the soil, this continues in the following weeks until flowering Weeding was initiated manually throughout the duration of the study to avoid the competition of weeds for better growth and development of the plants. Physical method of controlling insect through hand picking was employed, but when signs of severe insect attack and symptoms of plants were observed application of natural insecticide was done.

The fruits were harvested as they reach commercial maturity. This was started 41 days after sowing (DAS). All fruits of the non-sample plants per treatment were likewise harvested. Harvesting was done weekly by cutting the peduncle with a sharp knife.

The harvested fruits were sold to the students, staff and faculty of the school per kilogram at prevailing price in the locality.

\subsection{Data Gathering Procedure}

- Number of leaves at maturity (pcs) - This was done by counting the number of leaves in each sample plant in the different replications and treatments.

- Number of fruits (pcs) - This was done by counting the number of fruits per sample plant in the different replications and treatments.

- Length of fruits $(\mathrm{cm})$ - The breadth side of a fruit sample from the sample plants was measured.

- Diameter of fruits ( $\mathrm{mm}$ ) - This was done by measuring the center width of the fruit samples. 
- Number of damaged fruits (pcs) - This was done by counting the number of damaged fruits caused by insect pests, and diseases in each sample plant.

- Number of undamaged fruits (pcs) - This was done by counting the number of fruits free from damage caused by insect pest, diseases and as tray animals during and after harvesting Table 1.

- Yield $\mathrm{kg} / \mathrm{ha}$ - This was computed by taking the actual total weight of fruits harvested in each treatment from the first to the last harvesting Table 2.

- Cost and return analysis (Php) - Cost of farm inputs was calculated based on the current prices. The total cost of production was subtracted from the gross income to get the net income, after which the return of investment was determined.

Table 1. ANOVA of the number of undamaged of fruits of the cucumber

\begin{tabular}{|c|c|}
\hline $\mathrm{T}_{0}$ & $5 \mathrm{a}$ \\
\hline $\mathrm{T}_{1}$ & $12.67 \mathrm{~b}$ \\
\hline $\mathrm{T}_{2}$ & $11.33 \mathrm{~b}$ \\
\hline $\mathrm{T}_{3}$ & $14.33 \mathrm{~b}$ \\
\hline $\mathrm{CV}(\%)$ & 25.9 \\
\hline
\end{tabular}

Treatment means carrying the same letter are not significantly different $-*$ significant
Table 2. ANOVA yield kg/ha

\begin{tabular}{|c|c|}
\hline $\mathrm{T}_{0}$ & $3.91 \mathrm{a}$ \\
\hline $\mathrm{T}_{1}$ & $5.18 \mathrm{a}$ \\
\hline $\mathrm{T}_{2}$ & $6.23 \mathrm{a}$ \\
\hline $\mathrm{T}_{3}$ & $10.52 \mathrm{~b}$ \\
\hline $\mathrm{CV}(\%)$ & 19.4 \\
\hline
\end{tabular}

Treatment means carrying the same letter are not significantly different $-* *$ highly

\subsection{Statistical Tool and Analysis}

The data gathered were analyzed following the Analysis of Variance (ANOVA) of the Randomized Complete Block Design which determined if there were significant differences among the treatment means. The Least Significant Difference (LSD) was used to compare the different treatment means especially to determine which among the treatment means really differ.

\section{Results and Discussion}

\subsection{Number of Leaves of Cucumber at Maturity}

The Figure 1 shows that $\mathrm{T}_{1}$ (with 201 leaves) attained the highest number of mean leaves at maturity followed by $\mathrm{T}_{3}$ (200 leaves), $\mathrm{T}_{2}$ (197 leaves) and $\mathrm{T}_{0}$ (167 leaves) respectively.

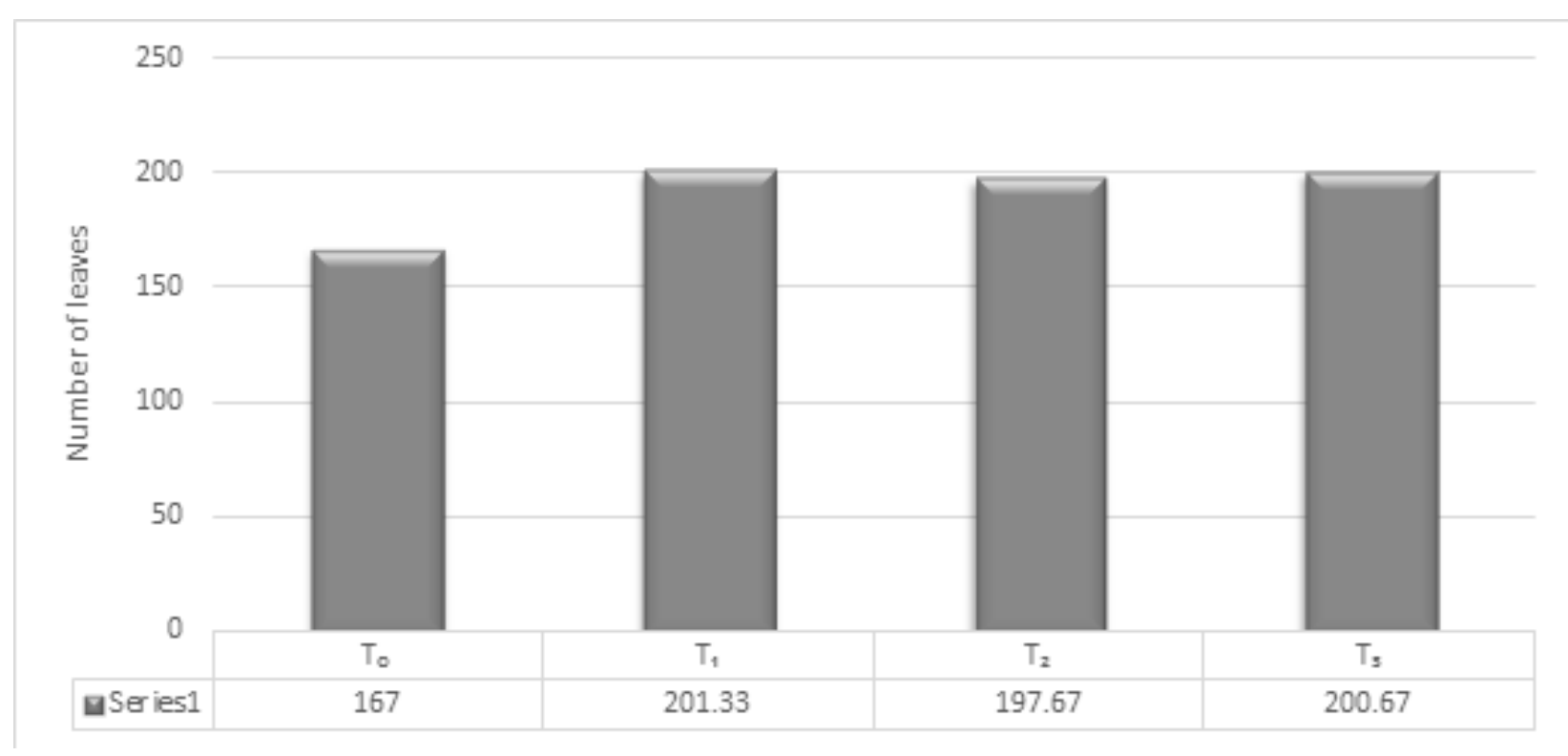

Figure 1. Number of leaves at maturity as affected by application of different levels of coir dust bio-organic fertilizer. 




Figure 2. Number of fruits as affected by application of different levels of coir dust bio-organic fertilizer.

Analysis of Variance reveals no significant differences among blocks and treatment means. This indicates that application of different levels of coir dust bio-organic fertilizer did not influence the number of leaves of cucumber at maturity.

\subsection{Number of Fruits of Cucumber}

Figure 2 shows that $\mathrm{T}_{3}$ (applied with 25 ton $\mathrm{BOF} / \mathrm{ha}$ ) obtained the highest mean number of fruits followed by $\mathrm{T}_{1}$, (applied with 15 tons BOF/ha), $\mathrm{T}_{2}$, (applied with 20 tons $\mathrm{BOF}$ )/ha and $\mathrm{T}_{0}$ (no application of $\mathrm{BOF}$ ) respectively.

Analysis of Variance of Table 3 reveals that there are significant differences among treatment means $(\mathrm{p}<0.01)$. This means that the application of different levels of coir dust bio-organic fertilizer significantly affects the number of fruits of cucumber. Further, least significant difference reveals that $\mathrm{T}_{3}$ obtained the highest number of fruits. This means that application of coir dust bio-organic fertilizer at 25 tons/ha can increase number of fruits of cucumber. This could be due to the increase nutrient uptake by the plants brought by beneficial microorganism. This is in agreement to the findings of $\frac{11}{}$. Increased absorption of nutrients caused by the bacterium's ability to produce hormones such as IAA. The existence of plant hormones produced by these bacteria will improve growth and development of root cells, to become more extensive absorption, which in turn increases plant nutrient uptake.
Table 3. ANOVA of the number of fruits of the cucumber

\begin{tabular}{|c|c|}
\hline $\mathrm{T}_{0}$ & $10.33 \mathrm{a}$ \\
\hline $\mathrm{T}_{1}$ & $15 \mathrm{a}$ \\
\hline $\mathrm{T}_{2}$ & $14.33 \mathrm{a}$ \\
\hline $\mathrm{T}_{3}$ & $25 \mathrm{~b}$ \\
\hline $\mathrm{CV}(\%)$ & 21.3 \\
\hline
\end{tabular}

Treatment means carrying the same letter are not significantly different $-* *$ highly

\subsection{Length of Fruits of Cucumber}

The Figure 3 displays that $\mathrm{T}_{3}$ has the highest mean length of fruits followed by $\mathrm{T}_{2}, \mathrm{~T}_{1}$ and $\mathrm{T}_{0}$ respectively.

Analysis of Variance reveals no significant differences among treatment means. This implies that the application of different levels of coir dust bio-organic fertilizer had no effect on the length of fruits of cucumber.

\subsection{Diameter of Fruits of Cucumber}

Figure 4 expresses that $\mathrm{T}_{3}$ has the highest mean diameter followed by $\mathrm{T}_{2}, \mathrm{~T}_{1}$ and $\mathrm{T}_{0}$ respectively.

Analysis of Variance reveals no significant differences among treatment means. The application of different levels of coir dust bio-organic fertilizer did not significantly affect the diameter of fruits of cucumber. 


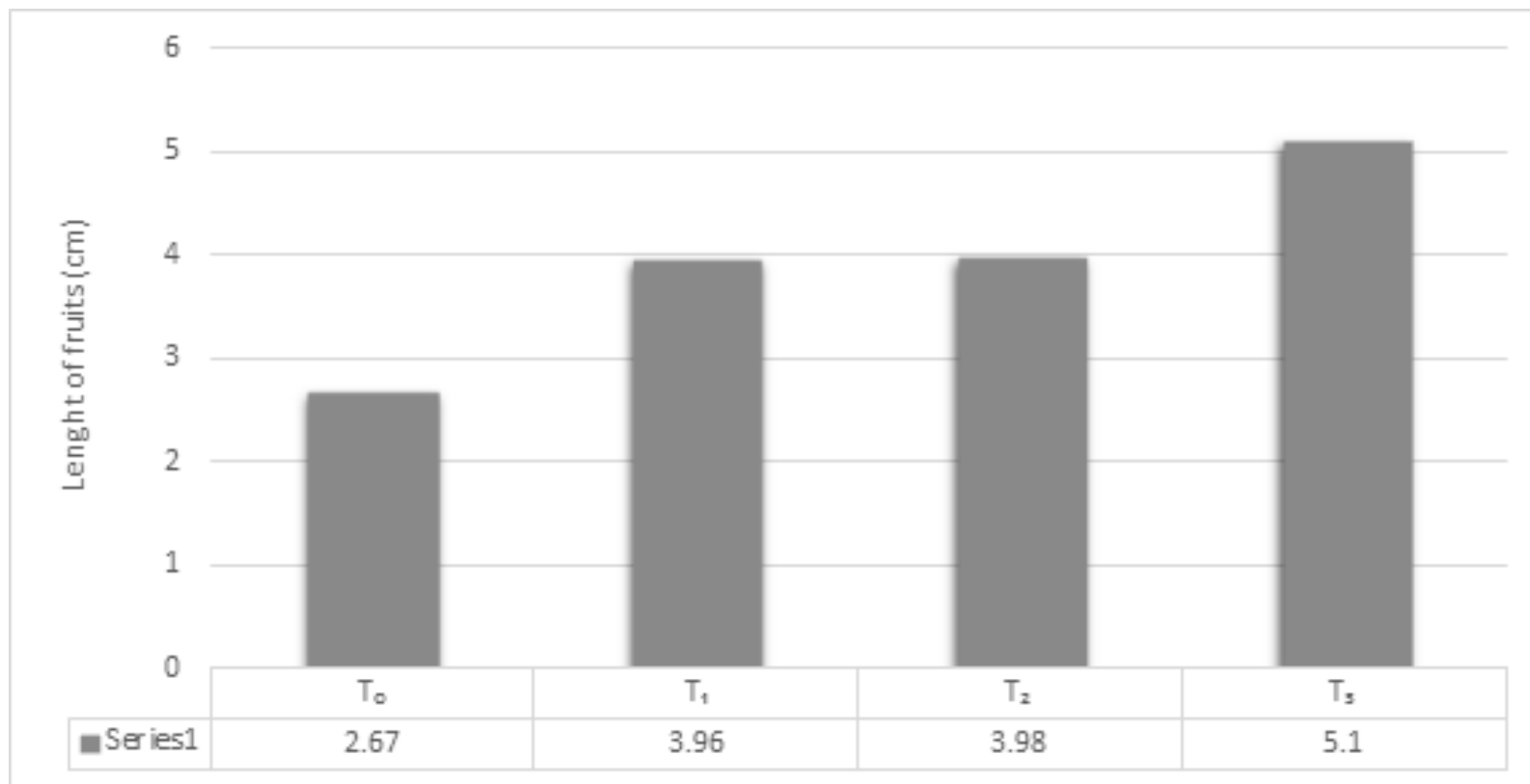

Figure 3. Length of fruits as affected by application of different levels of coir dust bio-organic fertilizer.

\subsection{Number of Undamaged Fruits of Cucumber}

Figure 5 shows that $\mathrm{T}_{3}$ obtained the highest mean number of undamaged fruits followed by $\mathrm{T}_{1}, \mathrm{~T}_{2}$ and $\mathrm{T}_{0}$ respectively.

Analysis of Variance reveals significant differences among treatment means $(\mathrm{p}<0.05)$. This means that the different levels of coir dust bio-organic fertilizer significantly influenced the number of undamaged fruits.
Further, least significant difference discloses that $T_{1}, T_{2}$ and $\mathrm{T}_{3}$ obtained the same number of undamaged fruits. This tells that application of 15 ton/ha, 20 ton/ha and 25 ton/ha of coir dust bio-organic fertilizer can produce the same number of undamaged fruits of cucumber, thus 25 ton/ha is more practical to use. This could be due to the plant growth promoting microorganisms present in the inoculant.

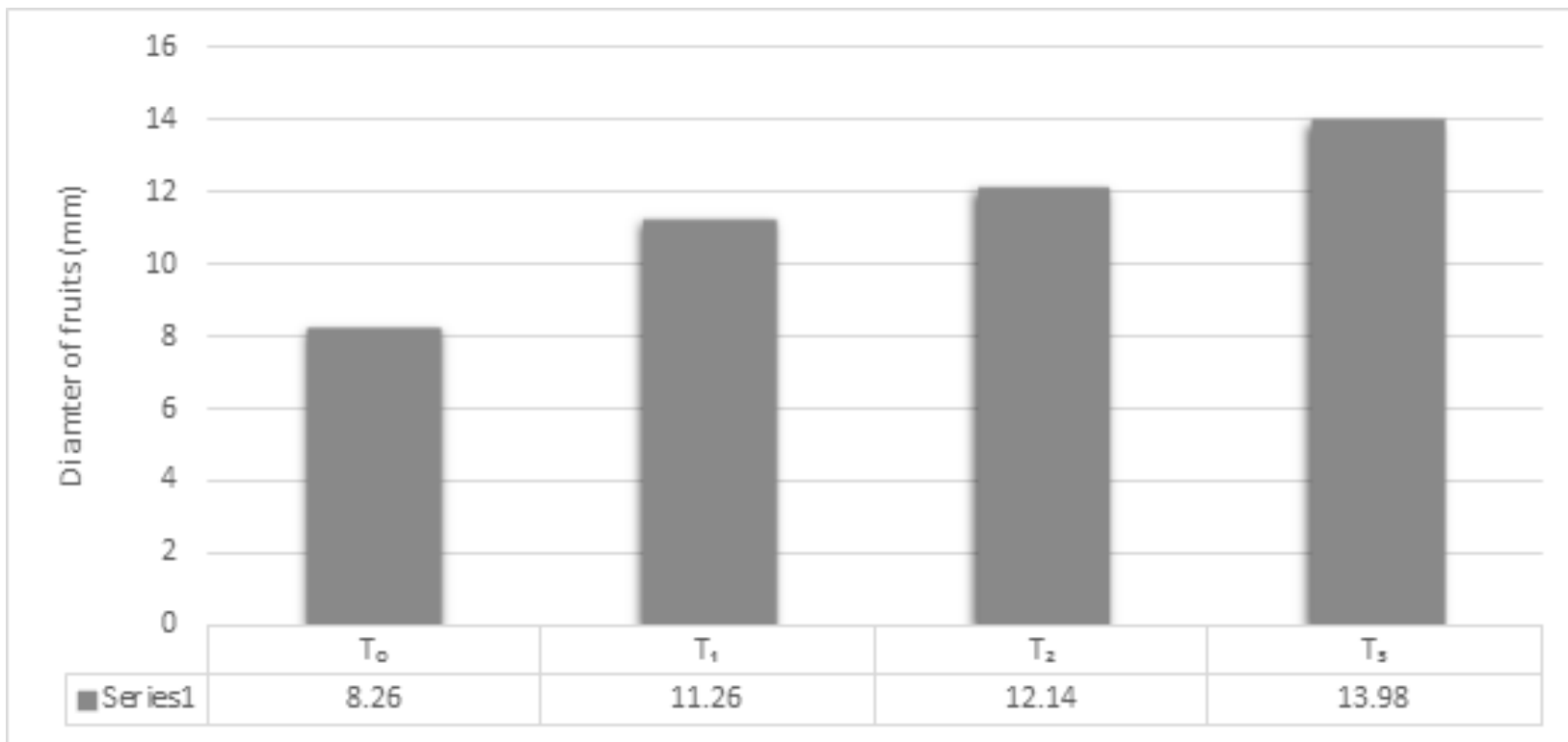

Figure 4. Diameter of fruits as affected by application of different levels of coir dust bio-organic fertilizer. 


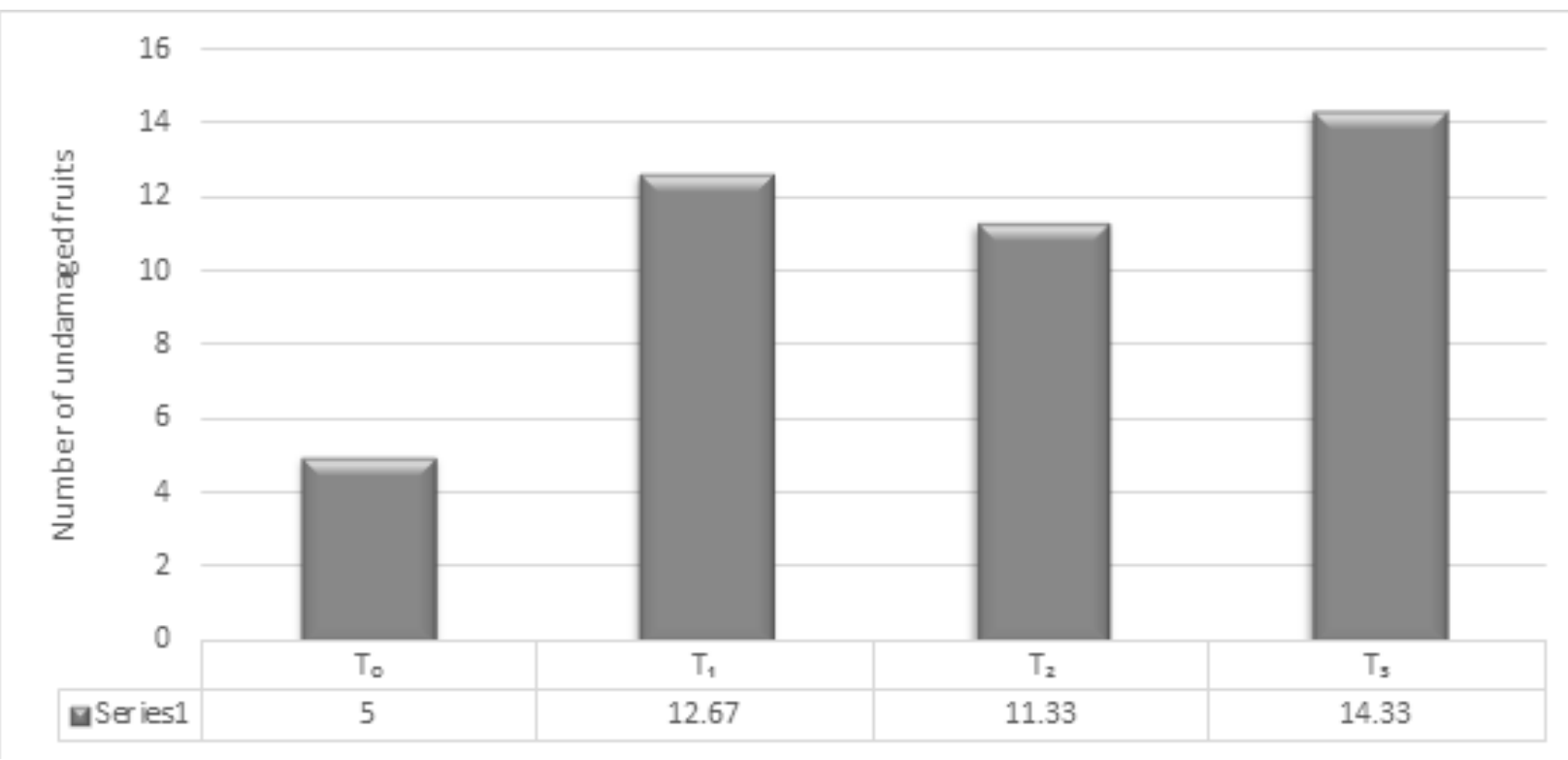

Figure 5. Length of fruits as affected by application of different levels of coir dust bio-organic fertilizer.

This is in agreement to the findings of Palacio who reported that plant growth promoting bacteria can produce vitamins for plants that can induce resistance against pathogens ${ }^{12}$.

\subsection{Number of Damaged Fruits of Cucumber}

The Figure 6 shows that $\mathrm{T}_{1}$ attained the lowest mean damaged fruits followed by $\mathrm{T}_{3}, \mathrm{~T}_{0}$ and $\mathrm{T}_{3}$ respectively.
Analysis of Variance reveals no significant differences among treatment means. This means that the application of different levels of coir dust bio-organic fertilizer did not significantly influence the number of damaged fruits of cucumber.

\subsection{Yield of Cucumber Plants}

As shown in Figure 7, $\mathrm{T}_{3}$ obtained the highest mean yield followed by $\mathrm{T}_{2}, \mathrm{~T}_{1}$ and $\mathrm{T}_{0}$ respectively.

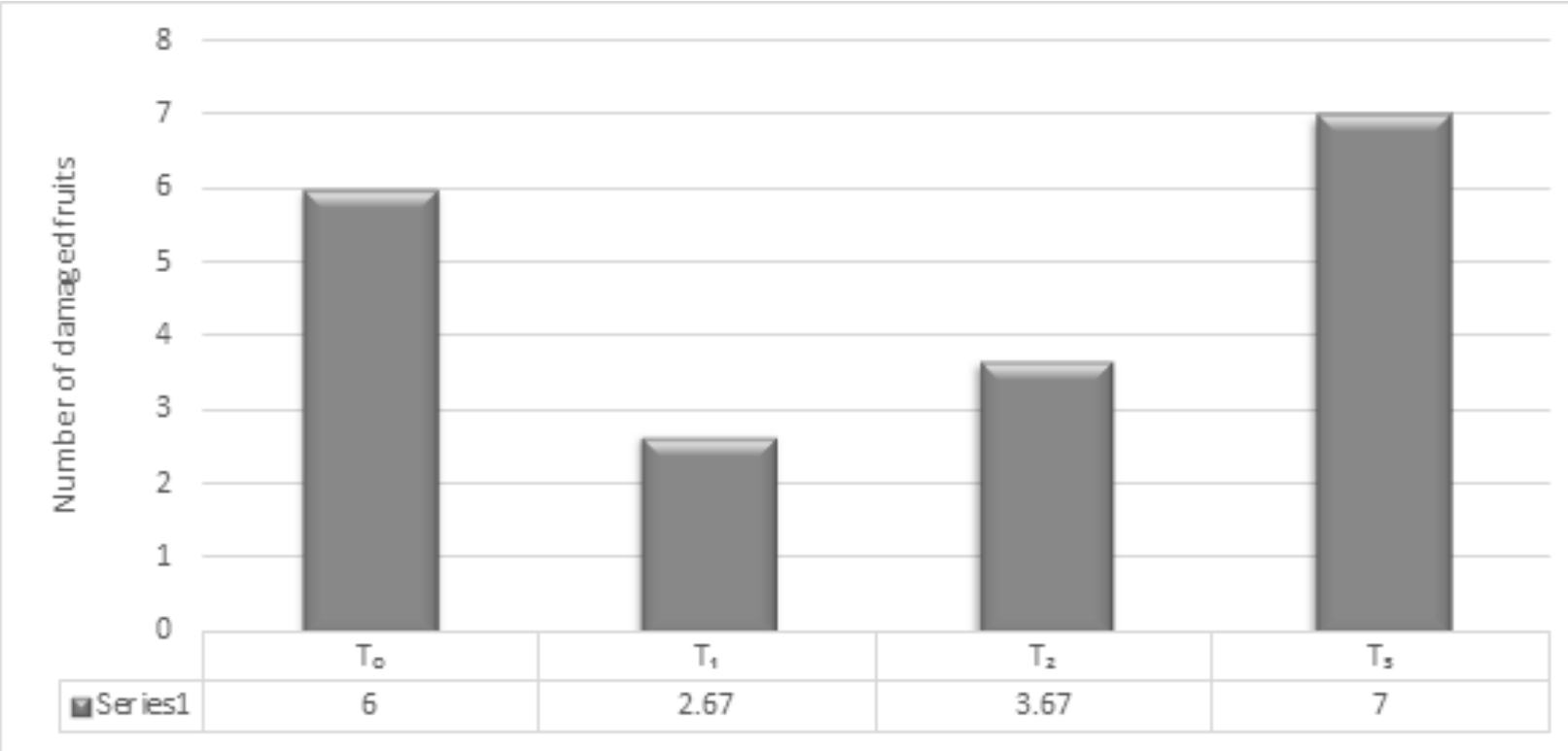

Figure 6. Number of damaged fruits as affected by application of different levels of coir dust bio-organic fertilizer. 


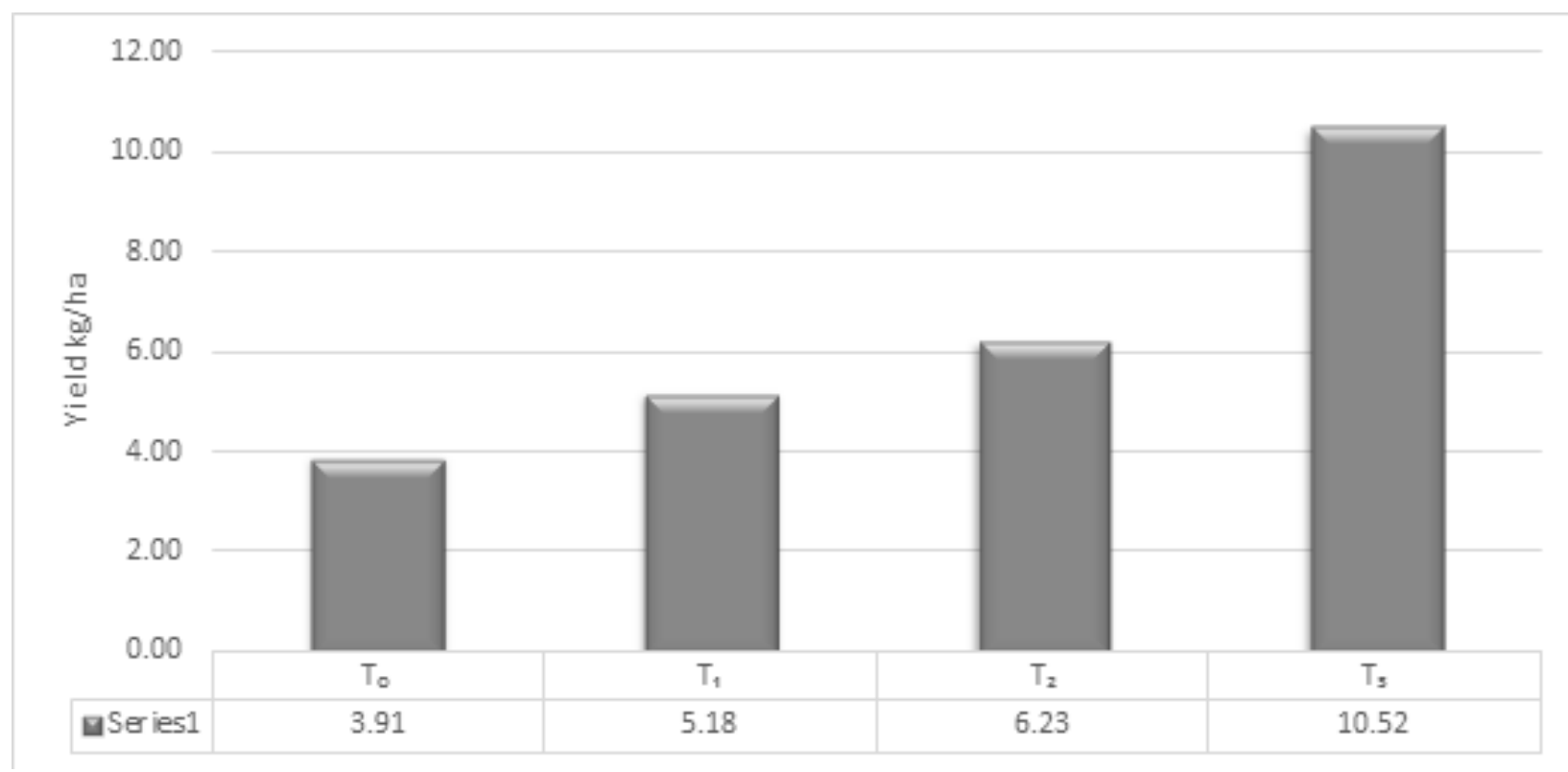

Figure 7. Yield of cucumber as affected by application of different levels of coir dust bio-organic fertilizer.

Analysis of Variance reveals that there are significant differences among treatment means $(\mathrm{p}<0.01)$. This indicates that the different levels of coir dust bio-organic fertilizer significantly affect the yield. Further, least significant difference reveals that $\mathrm{T}_{3}$ obtained the highest yield. This denotes that application of coir dust bio-organic fertilizer at 25 ton/ha can increase the yield of cucumber because of the presence of microorganisms in the bio fertilizer used.
This result conforms to the findings of Karthick, who reported that effective microorganism contains coexisting beneficial microorganism predominantly consisting of lactic acid bacteria, photosynthetic bacteria, yeast, fermenting fungi and actinomycetes that are claimed to enhance microbial turnover in soil and thus known to increase soil macronutrients and increases plant growth and yield $\underline{13}$.

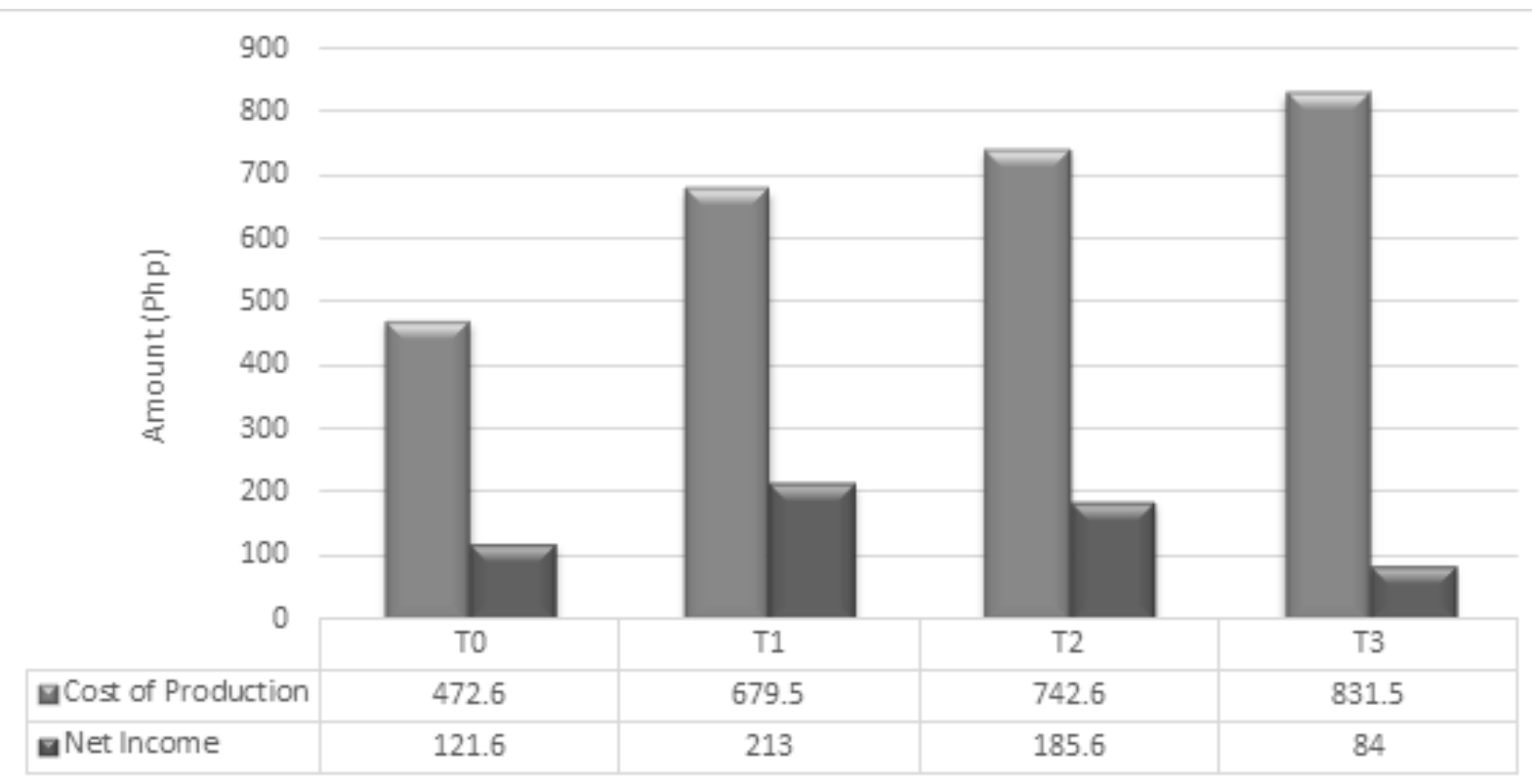

Figure 8. Cost of production and net income of the application of different levels of coir dust bio-organic fertilizer. 


\subsection{Cost and Return Analysis}

Figure 8 shows that $\mathrm{T}_{3}$ obtained the highest cost of production followed by $\mathrm{T}_{2}, \mathrm{~T}_{1}$ and $\mathrm{T}_{0}$ respectively. In terms of net income $\mathrm{T}_{1}$ obtained the highest followed by $\mathrm{T}_{2}, \mathrm{~T}_{0}$ and $\mathrm{T}_{3}$ respectively. As a result, $\mathrm{T}_{1}$ attained the highest ROI of $31.5 \%$, followed by $\mathrm{T}_{0}$ with $25.7 \%, \mathrm{~T}_{2}$ with $24.99 \%$ and the least is $\mathrm{T}_{3}$ with only $10.16 \%$ ROI.

\section{Conclusion}

The production of coir dust-based bio-organic fertilizer through bio conversion using Effective Microorganism (EM) is a worthy source of information to farmers to maximize the use of coco dust. Likewise, the utilization/ application of such bio-organic fertilizer can increase the number of fruits, undamaged fruits and yield of cucumber which is very favorable to cucumber growers.

\section{Acknowledgment}

The researchers wish to express their thankfulness to the Cagayan State University at Sanchez Mira administration for the motivation and moral support extended during the conduct of the study. To all the people who have spiritually supported them, thank you very much.

\section{References}

1. Ng SP, Tan CP, Lai OM, Long K, Mirhosseini H. Extraction and characterization of dietary fiber from coconut residue. Journal of Food, Agriculture and Environment. 2010; $8(2): 172-7$.

2. Study on the effectiveness of egg tray and coir fibre as a sound absorber. 2018. https://www.e3s-conferences.org/articles/ e3sconf/abs/2018/09/e3sconf_cenviron2018_02005/ e3sconf_cenviron2018_02005.html

3. Utility manages to work with asbestos in coaltar pipe wrap. 1996. https://www.researchgate.net/ publication/295315753_Utility_manages_to_work_with_ asbestos_in_coal-tar_pipe_wrap
4. Anderson RJ. The public health aspects of solid waste disposal. Public Health Reports. 1964; 79 (2):93-6. https://doi. org/10.2307/4592066

5. Rao PS. Quality of coir dust composts and their effects on the dry matter yield of maize. Journal of Tropical Agriculture. 2001; 39:24-7.

6. Kasthech B. Biofertilizer for crop production and soil fertility. Academic Journal of Agricultural Research. 2018; 6(8):299-306.

7. Earthworms mediated conversion of coir waste (Cocosnucifera) predigested. 2013. http://www. recentscientific.com/earthworms-mediated-conversioncoir-waste-cocos-nucifera-predigested-pleurotus-spundermonoculture-a.

8. Bramari SG, Anitha L. Formulation of potential vegetable waste compost in association with microorganisms and Spirulina platensis. Pelagia Research Library Asian Journal of Plant Science and Research; 2011. p. 49-57.

9. Smith AM, Ross AB. Production of bio-coal, bio-methane and fertilizer from seaweed via hydrothermal carbonisation. Algal Research. 2016; 16:1-11. https://doi.org/10.1016/j. algal.2016.02.026

10. Effective Microorganism (EM) activation procedure. 2014. http://agritech.tnau.ac.in/org_farm/orgfarm_effective $\% 20$ microorganism.html

11. Biofertilizer effects in combination with different drying system and storage period on growth and production of tomato plant under field conditions. 2007. https://www. ejfa.me/index.php/journal/article/view/526

12. Effect of organic and inorganic sources of fertilizer on growth, yield and fruit quality of eggplant (SolanumMelongena L). 2011. https://www.researchgate. net/publication/265944414_Effect_of_organic_and_inorganic_sources_of_fertilizer_on_growth_yield_and_fruit_ quality_of_eggplant_Solanum_Melongena_L

13. Evaluation of Effective Microorganism (EM) for treatment of domestic Sewage. 2011. https://www. researchgate.net/publication/229085089_Evaluation_of_ Effective_Microorganism_EM_for_treatment_of_domestic_sewage 